\title{
Asimetrías cerebrales en la psicopatía
}

\section{Brain asymmetries in psychopathy}

\section{Olga Lucía Valencia* \\ Universidad Complutense de Madrid, España}

Recibido: Abril 23 de 2007

Revisado: Mayo 5 de 2007

Aceptado: J unio 16 de 2007

\section{Resumen}

En el momento, hay un interés creciente por investigar y entender lo que ocurre en "la mente del psicópata", y las asimetrías cerebrales. El obj etivo del presente artículo es hacer una revisión teórica sobre las Asimetrías Cerebrales encontradas en estos suj etos, ante todo el desarrollo lingüístico y emocional asociado con la Psicopatía. Iniciamos con la definición de estilos afectivos, asimetrías cerebrales y regulación emocional, para luego describir los hallazgos respecto a las asimetrías en el procesamiento emocional y lingüístico en psicópatas. Finalmente, se aborda la relación entre las estructuras cerebrales y el trastorno.

Palabras clave: Psicopatía, asimetrías cerebrales, lateralización.

\section{Abstract}

At the moment, there is an interest to investigate the principals aspects about "the psychopath mind" and the brain asymmetry. The principal goal in this article is to check the linguistic and emotional development involved in psychopathy population. First, there is a definition of affective styles, brain asymmetries and emotional, and then is described the discoveries respect to the 
asymmetries in emotional and linguistic processing in psychopaths. Finally, the relation between the cerebral structures and the mental disorder is approached.

Key words: Psychopathy, asymmetries, lateralization.

\section{Introducción}

Las relaciones entre localización cerebral y psicopatología están en pleno desarrollo. Varias teorías sobre el procesamiento de la información sugieren que en alguna medida las funciones mentales dependen de una asimetría disfuncional de la distribución de los neurotransmisores en el cerebro humano Esto, sin olvidarnos del hecho de que en todas las funciones mentales intervienen ambos hemisferios y que aunque teniendo bien presente la asimetría hemisférica para una determinada función, cuando se produce, es más de grado que de clase (Portellano, 1992).

De la misma manera, hay muchas investigaciones que han demostrado que los psicópatas tienen un procesamiento lingüístico y emocional anormal, y una lateralización anormal del lenguaje, así como de otras áreas.

\section{Asimetrías cerebrales y la regulación emocional}

Un número considerable de investigaciones convergen en establecer que la psicopatología surge en parte debido a "un proceso de regulación deficiente", ya sea por el tipo de estrategia utilizada o como producto de una diferenciación afectiva poco desarrollada. A finales de la década de los 80 s, un grupo de investigadores concentró su atención en los aspectos corticales del procesamiento emocional. A partir de estudios en ratas y modelos de lesión en humanos, se comenzó a develar la participación de la corteza cerebral en las emociones, sobre todo de la corteza pre frontal en varias de sus porciones (orbito frontal, dorso lateral y ventromedial). La evidencia proveniente del análisis de pacientes con daño frontal sugería que la corteza prefrontal tendría un rol asimétrico en la participación de los procesos afectivos. De allí, ha surgido el concepto de Estilo Afectivo (Silva, 2005)

El Estilo Afectivo corresponde al rango de diferencias individuales en los múltiples componentes de las disposiciones anímicas y la reactividad afectiva. Diversas estructuras cerebrales se relacionan con el estilo afectivo, siendo categorizadas en dos sistemas que sustentan la motivación y la emoción: "El sistema de aproximación y el sistema de inhibición". El sistema de aproximación se ha descrito como favorecedor de conductas apetitivas y como generador de afectos positivos relacionados con el logro de metas. El sistema de inhibición facilita al organismo distanciarse de una fuente agresiva de estimulación, y organiza las respuestas apropiadas cundo es confrontado con estímulos amenazantes.

Se ha encontrado que la lateralización según el sistema emocional sólo existe para algunos de los componentes de estos circuitos, en particular la activación de la corteza pre frontal. Así, se concibe que la corteza pre frontal derecha estaría directamente implicada en el sistema de inhibición, mientras que la izquierda lo estaría en el sistema de aproximación. Esto quiere decir que los suj etos con asimetría derecha de la activación tónica de la corteza pre frontal tienen una tendencia a experimentar mayor intensidad de afecto negativo, en comparación con su contraparte izquierda. Así mismo, los individuos con la corteza pre frontal derecha tónicamente más activa están predispuestos a ser más sensitivos a los estímulos amenazantes, inhibiendo su conducta y experimentando más afecto negativo (Silva, 2005).

Davison, 1999, citado por Silva, 2005, ha sido enfático en subrayar que las asimetrías cerebrales 
funcionales deben ser entendidas dentro de un modelos de diátesis, esto es, que la asimetría frontal no es suficiente para causar estados emocionales específicos, sino que predisponen a responder bajo condiciones apropiadas de un modo u otro (Silva, 2005).

Existen datos convergentes sobre las consecuencias que tienen sobre la afectividad los diferentes patrones de asimetrías cerebrales.

\section{Regulación emocional y estilo afectivo}

Existen evidencias que muestran los procesos que ocurren durante la regulación de emociones negativas. Estudios de laboratorio han develado que la regulación emocional toma lugar al mismo tiempo que la corteza prefrontal "controla" la activación de la amígdala. Específicamente, la disminución voluntaria de las emociones negativas se relaciona con cambios en la actividad neuronal de la amígdala.

En otras líneas de desarrollo se han identificado diferentes consecuencias en la "efectividad" de la regulación, dependientes de los niveles de actividad tónica de la corteza pre frontal. Específicamente los sujetos con activación tónica frontal asimétrica derecha presentan dificultades para regular emociones negativas, en comparación con su contraparte asimétrica izquierda. En otras palabras, el tiempo que toma en recuperarse de un afecto negativo está asociado a las diferencias en las asimetrías pre frontales, donde los sujetos con asimetrías derechas tienen mayor dificultad en terminar con una emoción negativa una vez que ha comenzado. El patrón antisocial se caracteriza por: a) Una desinhibición comportamental y disfunción prefrontal, y b) disfunción del hemisferio izquierdo, o alternativamente, una lateralización reducida para las funciones lingüísticas (Matta, 1999)

Los procesos de inhibición y desinhibición son básicos para la adaptación. A veces, un comportamiento de aproximación puede ser selectivamente inhibido por la presencia de claves o anticipación de castigo. La falla primaria del psicópata es que carece de inhibición en situaciones en donde tanto la recompensa como el castigo son posibles y, cuando esto ocurre, los psicópatas parecen enfocar sobre las posibilidades de recompensa e ignorar las de castigo. Esto puede estar relacionado con la ausencia de culpa o remordimientos (Matta, 1999).

\section{La psicopatía: procesamiento lingüístico y emocional}

La psicopatía es un trastorno socialmente devastador, definido por la constelación del afecto, características interpersonales y conductuales que incluyen egocentrismo, impulsividad, irresponsabilidad, emocionalidad poco profunda, pérdida de la culpa, pérdida de la empatía y el remordimiento, mentiras patológicas, manipulación y la persistente violación de las normas sociales (Bartol, Curt; Bartol, Anne 2006).

La psicopatía es un desorden de personalidad complejo de etiología desconocida. Los psicópatas son individuos locuaces, superficiales, impulsivos con pérdida de la empatía, de la culpa y de sentir remordimiento de sus actos y el daño que hacen a las otras personas. Por muchos años las investigaciones en psicopatía se han enfocado en caracterizar y dilucidar el papel que juegan los procesos emocionales en el desorden. En general estos estudios han mostrado que los psicópatas tienen dificultades en la entrada y entendimiento de los aspectos connotativos del estímulo afectivo (Kiehl, Smith, Mendrek, Forster, Hare and Liddle, 2004).

\section{Procesamiento anormal emocional y afectivo}

Mientras el procesamiento del lenguaje es generalmente superior en el hemisferio izquierdo, el procesamiento emocional particularmente para emociones negativas, es generalmente superior en el hemisferio derecho (Hiatt, Lorenz y Newman, 2002). Hay estudios que de acuerdo con lo mencionado antes, plantean que la psicopatía está asociada con el procesamiento anormal de material verbal afectivo. 
En un estudio realizado por Williamson, Harper and Hare, 1991, se eligieron como suj etos experimentales a 16 reclusos entre 18 y 41 años, diagnosticados con psicopatía en la PCL de Hare, y sujetos no psicópatas, para que hicieran una Tarea de Decisión Léxica (TDL), así como su Tiempo de Reacción (TR), y los Potenciales Evocados (PE). Estas medidas se tomaron como respuesta a una serie de palabras grabadas con sentido afectivo, comparadas con palabras neutrales y palabras sin sentido (pronounceable nonwords). Los resultados apoyan las predicciones de que los psicópatas mostrarían menos conducta entre palabras neutras y afectivas que los no psicópatas. Las respuestas dadas en las TDL de los no psicópatas fueron significativamente más rápidas y relevantes, y los componentes de IOS PE fueron significativamente más largos. En contraste, los psicópatas tuvieron fallos para mostrar facilitación en el TR, así como en la amplitud de los Potenciales Evocados para las palabras afectivas.

Cleckley, 1976 citado por Day, y Wong, 1996, afirmó que aunque los psicópatas son capaces de entender el significado literal (denotativo) del lenguaje, ellos son incapaces de apreciar su significado emocional (connotativo). La evidencia empírica acumulada apoya el punto de vista de Cleckley de que los déficits emocionales descansan en el núcleo de la psicopatía. Comparados con los no psicópatas, los psicópatas demostraron reactividad autonómica disminuida ante una variedad de situaciones que provocan miedo y ansiedad, como la ausencia de sobresalto durante la exposición a una diapositiva no placentera, y fallos al mostrar el patrón típico de respuesta diferencial a palabras con contenido emocional y sin este.

En un estudio realizado por Day, y Wong, 1996, se encontraron asimetrías preceptúales anómalas para estímulos negativos en psicópatas. En este estudio, cuando se procesaba el material emocional negativo, los psicópatas comparados con los no psicópatas dependían menos de los procesos emocionales connotativos basados en el hemisferio derecho, y más sobre los procesos lingüísticos denotativos basados en el hemisferio izquierdo.

En este estudio se utilizó un taquitoscopio bilateral para examinar el procesamiento lateral de rostros y palabras emocional es negativas y neutras en psicópatas y no psicópatas. Se predecía que los psicópatas, (quienes no eran empáticos, se mostraban insensibles, y emocionalmente fríos), dependerían mas que los no psicópatas del hemisferio derecho, decodificando estrategias que acentúan el significado connotativo emocional de los estímulos. En cambio se esperaba que ellos dependieran más de la decodificación lingüística por medio de estrategias asociadas con el hemisferio izquierdo.

Hay que señalar que los sujetos diagnosticados con psicopatía fueron evaluados con la PCL. Se prepararon dos tareas con taquitoscopio análogas (con palabras y con rostros). La precisión y los tiempos de reacción de las respuestas de los presos, se midió al pedir a estos cual de los dos estímulos presentados bilateralmente (uno neutral y uno emocional) fue el estímulo predominante. Las diferencias en el procesamiento lateral entre los dos grupos surgieron en la tarea de palabras, pero no en la de rostros, dando soporte parcial a las hipótesis experimentales. Los psicópatas también mostraron más baja responsividad emocional generalizada, que los no psicópatas, en lo relacionado con la medida de la intensidad del afecto.

Los resultados aportados por Day, y Wong, 1996, fueron, como se predecía, que los sujetos no psicópatas fueron mas precisos y mas rápidos en el procesamiento de palabras emocionales negativa en el campo visual derecho que en el campo visual izquierdo. Los psicópatas en cambio, no mostraron ventaj a significativa según el campo visual. El hemisferio derecho parece ser especializado para el procesamiento del significado emocional de los estímulos lingüísticos. Además los psicópatas difieren de los no psicópatas en fallos para demostrar las ventaj as en el campo visual izquierdo cuando se procesan palabras con contenido emocional. 
Brody, 1987, citado por Day, y Wong, 1996, encontró que en participantes normales la presentación de palabras con contenido emocional mejoró la precisión y el tiempo de reacción durante las presentaciones en el campo visual izquierdo, pero que estas se reduj eron durante las presentaciones en el campo visual derecho. Los resultados de este experimento sugieren que los psicópatas no pueden demostrar este patrón.

La hipótesis de que los rostros emocionales negativos producirían una ventaja mas débil en el campo visual izquierdo de psicópatas que en no psicópatas no se confirmó. Los datos sugirieron que el procesamiento anómalo del material emocional en psicópatas puede ser restringido al dominio lingüístico. Estos mostraron menos reacciones emocionales en cuanto a intensidad del afecto que los no psicópatas. Esto se explica por las características ya mencionadas de pérdida del afecto y emocionalidad plana (Cleckley, 1976, citado por Day, y Wong, 1996).

El procesamiento lateral anómalo del lenguaje en el psicópata ha sido interpretado como indicador de que los psicópatas son menos lateralizados en su hemisferio izquierdo para el procesamiento de estímulos lingüísticos. Los resultados sugieren que una tarea en la cual los no psicópatas demostraron ventajas en el hemisferio derecho para procesar lenguaje emocional también demuestra menos ej ecución lateralizada (Day, R y Wong, S 1996).

Los fallos en los psicópatas para demostrar superioridad en el hemisferio derecho sobre la tarea ofrece alguna evidencia preliminar de que la cualidad emocional de los estímulos preferencial-mente decodificados por el hemisferio derecho puede ser menos saliente en los psicópatas (Day y Wong 1996).

Otro estudio sobre lateralización en el procesamiento de la emoción en psicópatas, fue el desarrollado por (Hiatt, Lorenz y Newman, 2002). Se utilizó el conocido método de escucha dicótica, para examinar las asimetrías hemisféricas, basados en el principio de que la entrada auditiva en cualquier oído está más fuertemente representada en el hemisferio contra lateral, debido al mayor fortalecimiento y preponderancia de las proyecciones auditivas contra laterales. La ejecución asimétrica indica una mayor eficiencia para el procesamiento por el hemisferio contralateral para una escucha más precisa. Basados en el funcionamiento lingüístico y emocional anormal, se espera que los psicópatas demostraran menos especialización hemisférica que los no psicópatas para el reconocimiento de tonos de palabras y emociones.

Contrario a lo que se esperaba, los individuos psicópatas tuvieron una ventaja en la escucha derecha para tarj etas de palabras. Al mirar el grupo de comparación, revela que no hay evidencia para la lateralidad reducida para tarjetas de palabras. Los resultados no confirman la hipótesis de que los psicópatas mostrarían lateralización del lenguaje reducida.

En contraste los psicópatas demostraron una ventaja más pequeña en la escucha izquierda que los del grupo control para la detección de tarj etas con estímulos emocionales. De manera acentuada, la lateralidad reducida en psicópatas en las tareas con estímulos emocionales, reflejan ejecución normal de la escucha izquierda, pero ejecución superior al compararlo con el grupo control. Además de su asimetría reducida, los procesos emocionales en los psicópatas son más eficientes en el hemisferio derecho que en el izquierdo, y al igual que en el grupo control mostraron ventajas en el oído izquierdo. Así los psicópatas tienen una eficiencia normal para el procesamiento de tarjetas con estímulos emocionales en el oído izquierdo, pero más eficiencia de lo normal para las tarjetas emocionales presentadas por el oído derecho (Hiatt, Lorenz y Newman, 2002).

La buena ejecución de los psicópatas en tareas emocionales, puede parecer sorprendente dado sus características de déficits en el procesamiento de la información. Sin embargo su alta exactitud es consistente con la literatura que demuestra que los psicópatas no difieren del grupo control cuando se les pregunta sobre contenidos emocionales. 
Hay mucha literatura que explica la diferencia entre la habilidad del psicópata para reconocer las emociones, y el uso de la información dada. Una cosa es el proceso, y otra su utilización, y hay teorías sobre procesamiento emocional que explican esto. La habilidad normal de los psicópatas para detectar emociones en los ensayos con tarjetas, son consistentes con las observaciones clínicas, los modelos teóricos y los hallazgos empíricos previos (Hiatt, Lorenz y Newman, 2002).

\section{Procesamiento lingüístico anormal en psicópatas}

Hay muchos estudios que demuestran que el procesamiento anormal del lenguaje puede estar relacionado con la lateralización anormal del cerebro, y en sujetos psicópatas, se han encontrado deficiencias en el funcionamiento del hemisferio izquierdo. Veamos algunos experimentos que muestran evidencia empírica para esto.

Para la mayoría de los individuos diestros, el lenguaje es procesado más eficientemente en el hemisferio cerebral izquierdo que en el derecho. La especialización del hemisferio izquierdo es realizada en un procesamiento lingüístico superior de estímulos unilateralmente presentados en el lado izquierdo, opuesto al hemisferio derecho. Los psicópatas sin embargo, a menudo fallan en mostrar superioridad del hemisferio izquierdo para procesamiento del lenguaje (Hiatt, Lorenz y Newman, 2002).

Los estudios empíricos iniciales apuntan a aclarar que el deterioro cognitivo en la psicopatía está relacionado con lateralización hemisférica para estímulos del lenguaje. Numerosos clínicos notaron que la conducta actual de los suj etos psicópatas es a menudo fuertemente inconsistente con sus reportes verbales, llevando a especular que este desorden está asociado con anomalías del lenguaje. Investigaciones posteriores encontraron que dichas anomalías son más predominantes cuando se requiere que estos individuos ejecuten tareas que involucren procesamiento semántico (Kiehl, Smith, Mendrek, Forster, Hare and Liddle, 2004).
Un rasgo clínico notable encontrado en los psicópatas es el uso inesperado del lenguaje. Cleckley (1979) citado por Raine, O'Brien, Smiley y Scerbo, (1990) ha descrito esta característica: Su lenguaje es persuasivo, fluente y engañoso, y además, muestran una disociación curiosa entre los que ellos dicen sobre ellos mismos, y como ellos llegan a ser. Presentan mentiras patológicas, buena inteligencia, pero muy baja su capacidad de insight. Hare, (1988) citado por citado por Raine, O‘Brien, Smiley y Scerbo (1990) encontró que en las entrevistas, los sujetos no psicópatas, movían menos las manos que los sujetos psicópatas, y que presentaban a lo largo de la conversación muchos mas gestos y comportamientos mas exaltados.

Hare, (1998) citado por citado por Raine, O‘Brien, Smiley, y Scerbo, (1990) sugirió que la evidencia encontrada para explicar las diferencias en el procesamiento de material verbal podría reflejar lateralización débil de los procesos lingüísticos en psicópatas. Esta interpretación la dió como resultado de una tarea de escucha dicótica verbal administrada a adultos psicópatas. A los prisioneros se les hicieron 22 ensayos de tres pares de palabras de una sílaba las cuáles fueron presentadas de manera dicótica. Los sujetos se organizaron en tres grupos (alto, medio y bajo) basados en los puntajes de la PCL de Hare, y el diagnóstico de Conducta Antisocial según el DSM-IV. El grupo con psicopatía alta, estuvo menos lateralizado que el grupo con psicopatía baja. En la ejecución en general no se encontraron diferencias. Cuando se cambió de oído entre uno y otro ensayo esto no redujo la asimetría auditiva en psicópatas.

Una posible explicación para los hallazgos previos sobre procesamiento lingüístico anormal en psicópatas es que ellos están menos lateralizados para los procesos verbales (Raine, O’Brien, Smiley, y Scerbo, 1990). En esta línea de investigación, experimentando en psicópatas y no psicópatas se usaron tareas de escucha dicótica que consistieron en pares de estímulos vocales-consonantes alineados por sus características temporales. Esta tarea particular fue seleccionada porque tenía 
ventaj as sobre el procedimiento estándar de escucha dicótica usado por Hare y Mc Pherson (1984). Si los psicópatas habían reducido la lateralización para el habla, ellos deberían mostrar una reducción en las asimetrías auditivas en la tarea.

Una segunda meta de este estudio fue valorar si los hallazgos para adultos psicópatas se pueden generalizar a adolescentes psicópatas. Hare and McPherson (1984) encontraron que la asimetría reducida en psicópatas podría ser una función de diferencias individuales en la extensión por la cual la entrada de estímulos a lo largo de las vías auditivas ipsilaterales están suprimidas, más que hayan diferencias en la lateralización el lenguaje. Los resultados indican que en estos sujetos, hay una reducida asimetría auditiva en psicópatas, que indica que los psicópatas son menos lateralizados para los procesos lingüísticos. Desde el paradigma de que la escucha dicótica verbal es poco afectada por la dirección de la atención dirigida a un oído, la asimetría reducida es poco probable que sea debida a la atención selectiva hacia el oído izquierdo. Más que haber menos lateralización para los procesos del lenguaje, se dice que los psicópatas tienen por un lado, disfunción del hemisferio izquierdo, o tienen un déficit de transferencia ínter hemisférica, esta es sólo una hipótesis.

Los datos sin embargo son consistentes con la noción de que los procesos lingüísticos son menos lateralizados en el hemisferio izquierdo en psicópatas, y quizás y reciben más representación cortical en el hemisferio derecho en relación con los no psicópatas. Este efecto no parece que sea propio de una modalidad específica; la misma reducción en las asimetrías hemisféricas ha sido recientemente encontrada en la modalidad visual en psicópatas (Reine, O'Brien, Smiley y Scerbo 1990).

La interpretación precisa de cómo se reduce la lateralización de los procesos lingüísticos no se ha definido hasta el momento. Las asimetrías reducidas en el lenguaje de los psicópatas, podría reflejar una reducción en el papel del lenguaje en la mediación y regulación de la conducta en el psicópata, y que estos, es menos probable que usen estrategias cognitivas y conductuales para depender de operaciones secuenciales y verbales del hemisferio izquierdo. Por ahora solo podemos especular, pero es razonable trabajar con las hipótesis que explican las asimetrías auditivas reducidas en psicópatas. Si esta posición es verdadera, se podría predecir que las asimetrías lingüísticas reducidas están particularmente asociadas con aquellos rasgos que reflejan peculiaridades lingüísticas en psicópatas (Reine, O‘Brien, Smiley y Scerbo 1990).

En otro estudio, realizado con escucha dicótica, se concluyó que la psicopatía puede estar asociada con lateralización débil de la función del lenguaje y que los psicópatas pueden tener más bajos recursos en el hemisferio izquierdo para el pensamiento del lenguaje, que los individuos normales (Hare y J utai, 1988).

El experimento se llevó a cabo con un procedimiento de Campo Visual Dividido (CVD) que se usó para investigar la organización cerebral de los procesos del lenguaje en Psicópatas. En un experimento realizado por Hare y J utai, 1988 se organizaron 4 grupos cada uno conformado por 13 varones diestros (Un grupo de no criminales(NC), y los otros tres de Psicopatía Alta(PA), Media (PM)y Baja (PB)según el PCL.

Los suj etos debían decidir si un sustantivo concreto presentado taquitoscopicamente en juntos, el campo visual derecho o el campo visual izquierdo, igualaba una "tarea pretrial", o fue sobresaliente en una categoría específica o una categoría abstracta. No hubo diferencias entre grupos en los Tiempos de Reacción. Los grupos no criminales (NC) y con baja psicopatía (BP) tuvieron más errores en el campo visual derecho (CVD) que en el campo visual izquierdo (CVI). Así se mostraba las ventajas esperadas con la categorización semántica con tendencia del campo visual derecho. Mientras que ocurrió lo opuesto con el grupo de Psicopatía Alta (PA) (Hare y Jutai 1988). En otro estudio, en la 
misma línea, parte de la hipótesis de que los psicópatas, pueden tener un deficiente procesamiento de la información en el hemisferio izquierdo; se utilizaron 26 psicópatas y 46 no psicópatas prisioneros, a los cuales se les pidió que realizaran tareas de atención dividida en las cuales los estímulos lateralizados aparecieron en los campos visuales izquierdo y derecho del monitor. Las tarjetas se presentaron primero en el campo visual derecho, para inducir la Activación Hemisférica Izquierda (AHÍ), procedimiento que se llevó a cabo de la misma manera en el campo visual izquierdo, para provocar el mismo nivel de activación, desde ambos hemisferios. Los psicópatas fueron menos exactos que los no psicópatas en la activación hemisférica izquierda. Así, los déficits de ejecución en psicópatas, fueron específicos, y se debieron a las condiciones asimétricas del hemisferio izquierdo (Llanes, Kosson, 2006).

\section{Estructuras cerebrales relacionadas con la violencia}

La teoría tradicional de la disfunción del hemisferio izquierdo en las bases de la violencia argumenta a favor de un daño estructural en ese hemisferio, a través de test neuropsicológicos, comparándolo con otros de daño cerebral. Una teoría más reciente, sutil -y potencialmente más plausiblede la violencia, tiene que ver con que estos individuos tienen procesos de discurso menos lateralizados (Matta, 1999).

Según la Teoria de Nachshon, citado por Matta, 1999, la disfunción del hemisferio izquierdo está vinculada a la conducta criminal. Esta teoría difiere de la de otras en dos puntos importantes: a) en contraste con las teorías frontales y frontotemporales límbicas, argumenta que hay una disrupción generalizada funcional en lugar de una disrupción estructural específica; y b), basa la evidencia para esta afirmación, no en el EEG o los tests neuropsicológicos tradicionales, sino en estudios de preferencia de lateralidad, asimetrías de la conductancia eléctrica de la piel, estudios de campo visual, dividido, y estudios de escucha dicótica. Nachsohn argumenta que la disfunción del hemisferio izquierdo predispone a la conducta criminal al disrumpir el control normal que el hemisferio izquierdo ej erce sobre los comportamientos impulsivos.

Esta teoría tiene algunos problemas: En primer lugar, los mecanismos de la conductancia eléctrica diferenciada en cada mano son confusas debido a que las conexiones cerebrales para estas funciones no están claramente establecidas. Por este motivo, es difícil sacar conclusiones sobre la lateralidad hemisférica en este sentido. En segundo lugar, aunque Nachsohn atribuye el concepto de impulsividad como un mediador entre la disfunción del hemisferio izquierdo y la violencia, ninguno de estos estudios ha verificado esta noción usando mediciones de impulsividad. En tercer lugar, los datos provenientes de la escucha dicótica, son usados para fundamentar un déficit global del hemisferio izquierdo, pero esto no es fácil de interpretar. Por ejemplo, Nachsohn argumenta que el oído izquierdo aventaja sobre tareas de tono dicótico en los agresivos violentos, mientras otros investigadores verían esto como una función normal para el material no verbal. En cuarto lugar, esta teoría debería predecir alteraciones EEG y de los PE lateralizadas, y tales cosas no han sido demostradas.

A pesar de estas críticas, la noción de una disfunción hemisférica global aún queda como una teoría factible de la violencia, pero necesita más investigación.

En relación con el daño frontotemporal-límbico izquierdo, Yeudall sostiene que la violencia está en parte determinada por el daño en las zonas izquierdas frontales, córtex temporal anterior, y las zonas amigdalares hipocámpicas del mismo lado. La evidencia empírica para esta hipótesis está basada en un gran número de estudios neuropsicológicos en sujetos habitualmente violentos y agresivos. Los estudios efectuados muestran un $76 \%$ de este tipo de disfunciones en criminales, localizadas en las regiones frontales y temporales del cerebro. De estos, el $79 \%$ mostraban anormalidades fronto temporales lateralizados a izquierda. Se han encontrado en adolescentes vio- 
lentos localizaciones similares de actividad dominante de lóbulo temporal izquierdo (Matta, 1999).

\section{Anomalías estructurales en el cerebro del psicópata}

Algunos autores plantean la hipótesis de que la Psicopatía está asociada con anomalías en el procesamiento semántico de la información lingüística. La resonancia magnética funcional se utilizó para caracterizar la arquitectura neuronal que fundamenta los procesos léxico-semánticos en individuos psicópatas criminales y se igualó con un grupo control. Los participantes ejecutaron una tarea de decisión léxica en bloques de estímulos lingüísticos alternados con un descanso en la condición de línea de base. En cada bloque los estímulos fueron: Palabras concretas y pseudopalabras (Kiehl, Smith, Mendrek, Forster, Hare and Liddle, 2004).

Consistente con la hipótesis, los individuos psicópatas en relación con los sujetos control mostraron ejecución más pobre para el procesamiento de Palabras Abstractas (PA). El análisis de los datos de la resonancia magnética para ambos grupos indican que el procesamiento de los estímulos de palabras comparado con los descansos en la condición de línea de base, estuvo asociado con activación neuronal en el Giro Fusiforme Bilateral, el Cíngulo Anterior, el Giro Temporal Medio Izquierdo, el Giro Temporal Superior Posterior Derecho y el Giro Frontal Inferior tanto izquierdo como derecho ((Kiehl, Smith, Mendrek, Forster, Hare and Liddle, 2004).

Los análisis confirman la predicción de que los psicópatas fallan para mostrar diferenciación neuronal apropiada entre los Estímulos Concretos y Abstractos en el Giro Temporal Anterior Derecho y el Córtex Circundante. Los resultados son consistentes con otros estudios de procesamiento semántico en psicopatía y fundamenta la teoría de que la Psicopatía está asociada con anomalías en el HD para dicho procesamiento (Kiehl, Smith, Mendrek, Forster, Hare and Liddle, 2004).
En otro estudio sobre asimetrías estructurales del hipocampo en psicópatas no exitosos partieron del fundamento de que las anomalías de la estructura y la función del hipocampo, relacionadas anteriormente con población psicopática agresiva, son conocidas. Este estudio realizado por Raine, A; Ishikawa, Arce, Lenez, Knuth, Bihrle, La Casse y Colleti (2004), determinó si en los resultados anteriores de una asimetría funcional izquierda mayor que derecha $(R>L)$ en delincuentes violentos presos, se generalizó la dominancia estructural en psicópatas presos no exitosos.

El volumen del hipocampo izquierdo y derecho se estudió a través de la imagen de resonancia magnética (MRI), usando a 23 sujetos de control, 16 psicópatas sin éxito y 12 psicópatas con éxito dentro de la comunidad.

Los psicópatas no exitosos mostraron una asimetría estructural exagerada del hipocampo $(R>L)$, en relación con los psicópatas con éxito y los sujetos de control, localizada en la región anterior del hipocampo. Este efecto no podría ser explicado por problemas ambientales ni de diagnóstico y se constituye como la primera imagen de análisis del cerebro de psicópatas con y sin éxito.

En el estudio, Raine, Ishikawa, Arce, Lenez, Knuth, Bihrle, La Casse y Colleti (2004), se concluyó que las asimetrías atípicas del hipocampo anterior en psicópatas sin éxito pueden reflejar una anormalidad subyacente del neurodesarrollo, que interrumpe el circuito del hipocampo prefrontal, resultando en un trastorno del afecto, un contexto pobre del condicionamiento al miedo e insensibilidad ante las señales de captura. La búsqueda de la estructuras y funcionamiento del cerebro ha empezado a mostrar significativas debilidades neurobiológicas en grupos de psicópatas antisociales y agresivos. Aunque la mayoría de estos estudios han implicado el córtex prefrontal (Henry and Moffit, 1997 and Raine, 2002, citados por Raine, Ishikawa, Arce, Lenez, Knuth, Bihrle, La Casse y Colleti, 2004), hay un interés creciente en el rol de las estructuras temporo límbicas tales como la mediación del hipocampo en comportamientos antisociales y psicopáticos. 
En un nivel general del córtex temporal, las funciones anormales han sido halladas en grupos psicopáticos violentos, antisociales, usando la imagen de la resonancia magnética (MRI), la tomografía única de foto emisión (SPECT) y la tomografía de posición-emisión (PET) (Raine 2001, Amen 1996 J uhasz 2001, Seidenwurm 19897, Wong 1997 citados por Raine, Ishikawa, Arce, Lenez, Knuth, Bihrle, La Casse y Colleti, 2004).

La evidencia de los trastornos temporales y del hipocampo, a partir de imágenes del cerebro, es muy consistente gracias a los resultados del electroencefalograma (EEG) y de estudios neuropsicológicos que implican anormalidades del lóbulo temporal en grupos violentos y antisociales debido a que el hipocampo está envuelto en la regulación de la agresión y en el condicionamiento del miedo contextual. Las anormalidades en el hipocampo e interrupción del circuito preforontal - hipocampal podrían contribuir a una desregulación afectiva e impulsiva, comportamientos desinhibidos del tipo ya observado en psicópatas (Raine, Ishikawa, Arce, Lenez, Knuth, Bihrle, La Casse y Colleti, 2004).

Se han encontrado asimetrías en la estructura y función del hipocampo. En términos estructurales, un estudio encontró que 6 de 10 pacientes forenses violentos con un diagnóstico de un desorden antisocial de la personalidad tenían unilateralmente una atrofia del hipocampo, con dos veces más lateralidad hacia el hemisferio izquierdo que hacia el derecho. En términos funcionales, un PET mostró asimetrías significativas en la función del hipocampo en agresores violentos, con 41 asesinos que mostraron una función reducida del hipocampo izquierdo y ampliado en el hipocampo derecho, comparado con 41 suj etos de control. Este efecto se constituía como una asimetría específica en la que la actividad del hipocampo izquierdo era relativamente más pequeña que el del derecho, más que diferencias de grupo que ocurrieron en ambos hipocampos. Esta asimetría no podría ser contada dentro de la historia de las lesiones cerebrales. De igual manera, usando el SPECT se encontró una asociación entre la activación reducida del hipocampo izquierdo (no del derecho), con altos puntajes de psicopatía en agresores violentos. De otro lado, ningún estudio de imagen estructural ha testado la hipótesis que los psicópatas tiene un inusual $R>L$ asimetría hipocampal (Cheterman, 1994; Raine, 1997 y Soderstrom, 2002 citados por Raine, Ishikawa, Arce, Lenez, Knuth, Bihrle, La Casse y Colleti, 2004).

Sobre la hipótesis de que el comportamiento antisocial psicopático puede provenir de un neuro-desarrollo anormal, hay poca evidencia limitada que comprueba esto (Raine, 1995 citado por Raine, Ishikawa, Arce, Lenez, Knuth, Bihrle, La Casse y Colleti, 2004). El hallazgo de una asimetría de la estructura del hipocampo en la misma dirección de la R>L asimetría funcional del hipocampo encontrada en agresores violentos sería de interés porque tales asimetrías pueden reflejar una disrupción que afecta el neuro desarrollo de una manera normal, esto opuesto a la tesis de que procesos ambiental es tardíos reducen la bilateralidad hipocámpica o el volumen en uno de los hemisferios.

También se ha encontrado que el desorden del estrés postraumático (PTSD), ha sido asociado a una reducción del volumen del hipocampo y que el estrés temprano ha sido asociado con una atenuación del desarrollo del hipocampo izquierdo, y que de alguna manera los psicópatas tienden a ser expuestos a eventos traumáticos desproporcio-nados como abusos en la infancia (Robins 1999 citado por Raine, Ishikawa, Arce, Lenez, Knuth, Bihrle, La Casse y Colleti 2004). La estructura anormal del hipocampo puede en cambio, estar ligada al trauma de una historia de lesiones cerebrales. En un nivel psiquiátrico, la esquizofrenia ha sido asociada con $R>L$ asimetrías de la estructura del hipocampo (Keshavan 2002) y porque hay comorbilidad entre comportamientos antisociales y desórdenes esquizofrénicos (Volavka 1997 y Keshavan, 2002, citados por Raine Ishikawa Arce, Lenez, Knuth, Bihrle, La Casse y Colleti, 2004).

Aunque las anormalidades de la estructura del hipocampo en psicópatas no han sido muy investi- 
gadas, un gran espacio en blanco en la literatura es la más completa falta de conocimiento en un intrigante grupo de psicópatas con éxito quienes se salvaron de ser detenidos por sus crímenes, comparado con los psicópatas fallidos quienes fueron detenidos y hecho convictos. Un estudio previo mostró que los psicópatas con éxito tienen una carencia de los déficits de la función autonómica y ejecutiva que tradicionalmente han sido mostradas por adultos psicópatas institucionalizados. En cambio, los psicópatas fallidos muestran una debilidad psicofisiológica y neuropsicológica intrínsecas. A pesar de la evidencia en la diferenciación de los psicópatas con y sin éxito, no existen imágenes de estudios previas del cerebro que demuestren si las anormalidades cerebrales son similarmente específicas en los psicópatas fallidos. Debido a que el hipocampo está envuelto en el condicionamiento al miedo contextual, los individuos antisociales con debilidades del hipocampo pueden volverse insensibles a las señales que predicen el castigo y la captura y por consiguiente ser más dados a la aprehensión. Como consecuencia, las debilidades del hipocampo parece que marcan el carácter fallido (sin éxito), ya que psicópatas capturados y no psicópatas evaden la detección con mayor éxito (Raine, Ishikawa, Arce, Lenez, Knuth, Bihrle, La Casse y Colleti, 2004).

\section{Conclusiones}

Se han encontrado fallos en el procesamiento lingüístico y emocional en psicópatas, que coinciden con las características propias de este desorden, como el mostrarse encantadores, decir mentiras patológicas, ser manipuladores, y una ausencia de empatía hacia los otros.

En los procesos de regulación afectiva, una de las principales fallas en las personas antisociales y en los psicópatas, es que hay fallos en la corteza pre frontal, y dificultades para poner en marcha los mecanismos inhibitorios, que controlarían sus conductas.

La psicopatía está relacionada con un procesamiento anormal del material verbal afectivo, y que aunque pueden entender el significado denotativo del lenguaje, tienen fallos para apreciar el significado emocional. En general, se puede concluir que los psicópatas muestran mayor dificultad en el hemisferio derecho para procesar el lenguaj e emocional.

En cuanto al desarrollo del lenguaje, se puede decir, con suficiente evidencia empírica que, el procesamiento anormal del lenguaje está relacionado con lateralización anormal del cerebro, y que en los psicópatas hay fallos en el funcionamiento del hemisferio izquierdo. Todo esto coincide con las observaciones clínicas realizadas a este tipo de pacientes, que muestran que la conducta actual, difiere y es a menudo inconsistente con los reportes verbales que dan, y la reacción emocional que muestran.

Por último, en psicópatas se han encontrado fallas en el lóbulo prefrontal, así como anomalías en el hemisferio derecho para el procesamiento semántico. En psicópatas no exitosos, se encontró fuerte asimetría estructural en el hipocampo, pero no es de la misma manera en psicópatas exitosos.

\section{Referencias}

Bartol, Curt; Bartol, Anne (2006) Current perspectivas in forensic psychology and criminal justice (p. 107-117) Thousand Oaks, CA. U.S Sage Publications. INC. (Monografía).

Day, R; Wong, S (1996) Anomalous Perceptual Asymmetries for Negative Emocional Stimuli in the Psychopath. Journal of Abnormal Psychology, 105 (4) 648-652.

Hare, R; J utai, J (1988) Psychopathy and Cerebral Asymmetry in Semantic Processing. Personality and Individual Differences, 9, 329-337.

Hare, R. D; Mc. Pherson, L (1984) Psychopathy and perceptual asymmetry during verbal tasks. J ournal of Abnormal Psychology, 93, 141-149. 
Hiatt, K; Lorenz, A y Newman, J (2002) Assessment of emotion and language processing in psychopathic offenders: Results from a dichotic listening task. Personality and Individual Differences, 32, 1255-1268.

Kiehl, K; Smith, A; Mendrek, A; Forster, B; Hare, R and Liddle, P (2004) Temporal Lobe Anormalities as revealed by functional magnetic resonance imaging. Psychiatry Research: Neuroimaging, 130 (1), 27-42.

Llanes, S; Kosson, D (2006) Divided Visual Attention and left hemisphere activation among psychopatic and non psychopatic offenders. J ournal of Psychopathology and Behavioral Assessment, 28 (1), 9-18.

I Conferencia presentada en el Simposio Regional de la WPA organizada por la AAP el 22 de octubre de 1999. Mesa Redonda: "Personalidades Psicopáticas: tres enfoques" Ponencia: Neurobiología del Psicópata. Eduardo Matta.
Portellano, J.A (1992) Introducción al estudio de las Asimetrías Cerebrales. Colección Neurociencia. Editorial CEPE. Madrid.

Raine, A; O‘Brien, M Smiley, N and Scerbo, A (1990) Reduced Lateralization in Verbal Dichotic Listening in Adolescent Psychopaths. J ournal of Abnormal Psychology (3), 272-277.

Raine, A; Ishikawa, S; Arce, E; Lenez, T; Knuth, K; Bihrle, S; La Casse, L y Colleti, P (2004) Hippocampal structural asymmetry in unsuccessful psychopaths. Biological Psychiatry, 185-191.

Silva, J. (2005) Regulación emocional y psicopatología: el modelo de vulnerabilidad/ resiliencia. Rev. Chil. Neuro-psiquiatr, 43 (3), 201-209.

Willliamson, S; Harper, T y Hare, R (1991) Abnormal Processing of Affective words by Psychopaths. Psychophysiology, 28 (3), 260-273. 